\title{
VERSITA
}

\section{DOES INDIVIDUAL MORAL RESPONSIBILITY LEAD TO COLLECTIVE MORAL RESPONSIBILITY FOR ORGANISATIONS?}

TAMARA AYRAPETOVA

\section{BACKGROUND}

In this essay the author will look at ethics and its application to business operations on different levels (individual, corporate, and systematic issues). She will devote specific attention to the way individual and collective responsibility is linked to each other. What is individual responsibility and does collective responsibility has a place to be in today's business world.

To start this essay the author would like to look at the ethics itself, what is it and how it affects our vision of things. Ethics is a part of philosophy that deals with our moral obligations and beliefs. As most of the philosophy it starts from setting questions, which are in need of answers. Those questions in ethics lead to determining what is 'right' and what is ' wrong' from the moral sense. Ethics tries to question things or actions, which sometimes people predetermine to be morally 'right' or 'wrong' just because they think that those are like that by definition. Ethics seeks for rational and logical conclusions, in the actions and decision which we are facing every day. The interesting fact about ethics is that it does not open anything new to us. What it does is question and examine things we already know. According to Socrates, "the unexamined life is not worth living"(Plato, 5e-6a, after 399 BC).

Ethics is mainly dealing with the moral norms and moral duties individuals have to each other. Ethics investigates how relevant or irrelevant human actions are in reference to the consequences they bring (consequentialism) or the rules and principles governing them (categorical or deontological approaches). Ethics is a normative study, which means that it tries to come to some normative conclusion, in most cases on whatever is 'right' or 'wrong', and this is what makes ethics so important in our lives.

In all the world and in all of life there is nothing more important to determine than what is right. Whatever the matter which lies before us calling for consideration, whatever the question asked us or the problem to be solved, there is some settlement of it which will meet the situation and is to be sought..." (Lewis, 1995) 
The word "ethics"takes its roots from the Greek word ethos, whereas "morality"comes from Latin word "mores". Both of the words take their meaning from the idea of "custom" or moral behavior. (Pojman er Fisher, "Ethics Discovering Right and Wrong", 6e) Even though in general ethics is about our moral values and actions, it is important to remember that those are defined differently depending on the theories (deontological and teleonotological).

This essay will link the ethics of individual responsibility with the collective moral responsibility in the organisations. What the author finds essential to understand in this topic is the notion of individual responsibility when one enters the business environment. What role he/she plays and on which behalf the actions are performed is paramount. It is also crucial to see the way individuals are connected in organisational context and if this connection actually means that we can have collective moral responsibility and as the result to CSR (Corporate Social Responsibility).

To start a discussion on wherever individual moral responsibility leads to collective moral responsibility and is there any collective responsibility at all? The author of this essay would like to first of all define what is a moral responsibility and discuss the concept of moral agency and individual moral responsibility as well as their direct connection. Then she will look at the concept of collective moral responsibility and the way it is built on the previous concepts. She will also look at the concept of CSR which is directly connected with the collective moral responsibility in organisations. In the end, a conclusion will be drawn.

\section{MORAL RESPONSIBILITY}

The concept of moral responsibility is essential to understand if we are talking about individual and collective moral responsibility. When any of us is judging any kind of action we usually tend to give this action a value of "good" or "bad" and assign a responsibility for this action to someone who was involved. Responsibility comes from moral obligations and certain commitments and obligations we have to each other. Those obligations might come from cultural, religious views, or some society standards.

"To be morally responsible for something, say an action, is to be worthy of a particular kind of reactionpraise, blame, or something akin to these-for having performed it"(Eshleman, 2009).

One of the key concepts one has to understand here is the difference between causal and moral responsibility. To understand the difference better let us look at the simple example:

1. The flood has been responsible for all of the damages in Prague.

2. The car crash damages due to the drunk driver.

One can see a very big difference between those two. The first example illustrates purely the connection between the hurricane and the harm whereas the second one also assumes obligations and other moral responsibilities towards the action. The concept of moral responsibility is very complex and consists of the following factors:

'(1) The concept, or idea, of moral responsibility itself;

(2) The criteria for being a moral agent;

(3) The conditions under which the concept of moral responsibility is properly applied, (e.g., a moral agent can be responsible for an action he/she has performed only if he/she performed it freely); and

(4) Possible objects of responsibility ascriptions (e.g., actions, omissions, consequences, character traits, etc.)' (Eshleman, 2009). 
Those conditions are building blocks of moral responsibility and are the key to understanding of individual and collective moral responsibility. As it has been mentioned above each action or obligation is assigned to specific moral agent, who either performs it or fails to perform it. In case of individual responsibility the connection between the action and moral agent is pretty straight forward; however when looking at the collective responsibility, the extent to which each member contributes to the decision and action is hard to observe. That is why there is a debate wherever one can call a group/collective a moral agent.

\subsection{A CONCEPT OF MORAL AGENCY AND INDIVIDUAL MORAL RESPONSIBILITY}

The concept of moral agency has a key role to play in ethics and the understanding of moral action and consequences of any act. It is mainly vital for assigning praise or blame. Moral agent in a simple meaning of this concept is a person or an entity performing an act, or deciding to perform some kind of action, which is ought to be taken as morally 'right' or 'wrong'. According to this concept a moral agent is acting upon some duties, obligations or set of moral rules he/she finds 'right'. Those standards and obligations might differ from person to person and are called either moral values or moral norms.

\section{"One who qualifies generally as an agent open to responsibility ascriptions (e.g., only beings possessing the general capacity to evaluate reasons for acting can be moral agents)" (Eshleman, 2009)}

There are different types of moral agents. Not always an agent has a free choice to make 'for' or 'against' a certain action he/she performs. An agent with free choice is called a 'Free Agent', and this type of agent can do as he/she wishes to do without any constraints or influences; however this does not include moral influences like codes of ethics and moral obligations. Understanding this concept is very important since moral agent can be responsible for an action only if he/she performed it freely.

\section{"Moral agent can be responsible for an action she has performed only if she performed it freely, where acting freely entails the ability to have done otherwise at the time of action" (Eshleman, 2009)}

According to Aristotle (384-323 BCE), a voluntary or also called free action has also another characteristic.

\section{"An agent must be aware of what it is she is doing or bringing into being" (Eshleman, 2009)}

This characteristic makes it harder to make someone liable for an act since they might not know exactly what they bring about but negative consequences may still be present.

Later the statement has been developed into more specific and in-depth, where a moral agent could only be responsible for an action if he/she possessed a capacity for the decision. This type of statement changes the picture of moral responsibility as a whole. It makes it harder, especially in collectives and groups, to find the one responsible for an action, but it also makes it fairer in a sense of overall responsibility. It also forwards the question of should the individuals in the collectives be held liable for their specific decisions and actions (which means no collective responsibility), or should the collectives or groups held liable for all of the actions individuals inside of it perform. To give a reasonable answer to this question one needs to investigate if collective moral responsibility can exist. 


\subsection{THE CONCEPT OF COLLECTIVE MORAL RESPONSIBILITY}

Collective moral responsibility refers to actions, which had been performed by more than one individual. It can be an organisation, team or other groups of people. Collective moral responsibility unlike the individual does not necessarily mean that there has been a contributory fault of the entire group, which makes it hard to assign responsibility and obligations for some of the decisions.

Collective moral responsibility has been always under a big discussion, and many philosophers hold that all of the actions still lead to individuals inside the collectives. One of the biggest discussions has been due to the concept of 'moral agency' and the existence of 'group intentions' and 'group decisions'. The second important discussion aroused about moral blameworthiness.

\section{CAN COLLECTIVES BE MORAL AGENTS?}

In the case of collective moral agency there are two types of views; some of the philosophers believe that collectives cannot be taken as moral agents, some that collectives are moral agents and as the result can be held responsible for the actions they perform. The important idea here is that if collectives are not moral agents we cannot assign any responsibility to them.

\subsection{ARGUMENTS FOR "COLLECTIVE MORAL AGENCY"}

There is a big discussion between professional about whether something like collective or group responsibility can exist. Some of the philosophers take their reasoning from the theory behind moral agency. They argue that groups of individuals cannot have collective actions and intentions.

H.D. Lewis (1948) highlighted that groups cannot hold beliefs or make choices since they do not have a mind of their own. Lewis also argued that "value belongs to the individuals and it is individuals who are the sole bearer of moral responsibility". The idea behind this argument is that of individualism, which holds that individuals should not be blamed on the bases of someone else's actions. This type of thought was held by most of the classical methodological individualists like Max Weber (1914) and H.D. Lewis (1948).

If this is true then no organisation or institution can be held responsible for the actions perform, since there is no such a thing as collective responsibility. However, this type of approach has been lately argued and according to J. Angelo Corlett (2001), there is collective responsibility since there is a collective action.

Collective action is an action caused by the beliefs and desires of the collective itself, whether or not such beliefs and desires can be accounted or explained in individualistic terms (Corlett 2001). Peter French also argues that collective responsibility should be true due to the fact that some of the actions cannot be assigned to individuals. Such actions most of the times are results of collective decision like "elections of the President".

According to Marry Lay (1987) one can have collective responsibility only when individuals in collective are related, which is possible in the cases of corporate social responsibility inside the organisations and institutions. May also sets 2 conditions:

1. The first condition is those individuals involved in collective action would be related in such a way so that they could not perform this action by their own.

2. The second condition is that some of the individuals will be authorised to represent their individual actions as the actions of the group (May, 1987). 
Both of these conditions can be easily applied in the working environment, where employees are related exactly in a way that they cannot perform certain actions by their own, as the result they cannot be responsible individually. Looking at the second point specific employees inside of organisation, do have ability to present their own actions as group actions, like actions of managers and CEOs.

\section{But even though we might have collective actions what about collective intentions and the group mind?}

Some philosophers stick to a classical believe that groups cannot have minds in any sense other than the minds of individuals inside the group, which makes it useless to talk about collective moral responsibility, when it again comes back to our individual obligations. The defenders of collective responsibility though say that there is a possibility of group intentions. David Velleman in his works calls this concept "truly plural subject", Raimo Tuomela defines "we intentions" and "collective subject", which can be also seen in the "Leviathan" by Thomas Hobbes (1651). The later works of Larry May and other philosophers argue that group intentions may not be necessarily of the same type as traditional individual intentions. This type of assumption brings the argument 'for' or 'against' collective moral responsibility on a new level. May (1987 and 2006) comes up with his own way of describing group intentions, which now combines both approaches of individualism and collectivism. Larry May (1987) calls these intentions "pre-reflective". What is specifically important here is that the origin of this type of intention comes from the relationship between the members of the collective, which again comes back to the earlier argument of May, where he says that collectives can be taken as a "moral agents" if and only if there is a relationship between them (ex. a connection where one is dependent on the other).

All of the defenders of collective moral responsibility though do not say that all of the groups are able to act collectively and have collective intentions. All that they say is that some specific kinds of groups can be acting collectively, and as the result be responsible for the consequences of their acts.

\subsection{ARGUMENTS AGAINST 'COLLECTIVE MORAL AGENCY"}

Many philosophers of mainly individualistic approaches argue that moral responsibility of a group or collective always comes back to the individual responsibility inside the collective. The argument is that collectives do not have an ability to make moral choices by themselves. H.D. Lewis (1948) argues that actions relate strictly to individuals and he also states that groups do not have minds of their own and due to this are not able to decisions and have beliefs. The same view is held by Watkins (1957). Most of the critics of collective moral responsibility look at the collective actions and forget to look at the nature of blame. R.S. Downie (1969) focused at the moral blameworthiness. The point he was trying to make is that collectives do not have moral faults, since they do not make moral choices. To have moral responsibility one must have blameworthiness and immoral decision (Downie, 1969). Other critics like Naverson (2002) argue that only the individual can have ' moral agency' and only moral agent can perform morally 'right' or 'wrong' acts.

According to the argument brought about by Larry May (1987), individuals do stay as the only moral agents, since they are the only agents who are able to perform actions. However, he gives a new view on this by saying that collectives are not that much agents, they are rather a 'process' which as the result produces actions. Those actions according to May are formulated by the structure of the corporation and can be called corporate actions. This type of agency is more an 'event agency', which means it is based on the performed activities and processes.

Most of the contradictors of collective moral responsibility still agree that in a limited number of cases it has a place to be. However, what they are trying to specify is that there are a number of mismatches arising when one admits that collectives do not have mental lives. 


\section{INDIVIDUAL TO COLLECTIVE MORAL RESPONSIBILITY THROUGH CSR}

Most of the time collective moral responsibility in organisations is represented by the sum of the responsibility of each individual member. This argument for collective moral responsibility is directly built on the individual responsibility, taking into account the roles and the hierarchy of decision making of the organisation. This concept is very logical when looking at it but makes it hard to quantify the degree of moral responsibility assigned to each individual. It is also true that till now there is no model which could help to prove this approach. In this essay the author decide to look from another perspective. She decided to look at the Corporate Social Responsibility and through this concept prove existence of Collective Moral Responsibility.

In the 20th century there has been a great change in the way cooperation work and grow. Due to their rapid development and growth, their activities and power largely increased. The society had started to be concerned with the way companies work and operate, specifically the harm they might bring to the society while performing their business activities.

Many people have noticed that the influence of the big organisations grew with the years, but the responsibilities for their actions still stayed in the boundaries of legislation of the land they are operating in. This has led to new discussion about new concept of corporate social responsibility of companies towards the society. The concept of corporate social responsibility has been firstly mentioned only in the 1960 s and has been very theoretically based through the 1990s. The big change came from the side of civil society groups, which were fighting for better management of the effects of the business operations.

The concept of corporate social responsibility is closely linked to the collective moral responsibility in organisations. When we are talking about making collectives liable/responsible for their actions most of the times we are talking about their obligations and behaviour towards society. Nowadays, we can see increasing attention of customers, employees, and other stakeholder groups towards the CSR of the organisations. CSR is a growing trend in today's business world. It is used for consumer branding, employer branding and is a key to a good reputation of an organisation. The existence of this concept is no more argued. Since we know that CSR exists, we can build this very simple logical assumption: "If collective moral responsibility would not exist, CSR would not have place to exist, since organisations are collectives. This can be transformed into a simpler sentence if collective responsibility then CSR."

\section{$q$ if $p$}

Where: $p$ is collective moral responsibility and $q$ is CSR

Assuming that $q$ is CSR and $p$ is collective moral responsibility; let us discuss this logical status by formalising it as follows:

\section{if $q$ then $p$}

Here it is important to mention concepts of 'necessary condition' and 'sufficient condition'. Necessary condition means that variable $X$ would not exists without variable $D$, in other words, an absence of $D$ would mean an absence of $X$. To say that $X$ is a sufficient condition of $D$ means that the existence of $X$ guarantees the presence of $D$. Looking at our implication we can say that $p$ is a necessary condition whereas $q$ is a sufficient condition.

Since $q$ (CSR) is sufficient condition, and we know it exists in various formats, then it would follow by modus ponens, that $p$ (collective moral responsibility) must also exist. 


\section{CONCLUSIONS}

The main aim of this essay was to investigate if individual moral responsibility leads to collective moral responsibility in organisations. Looking at everything covered in this essay the author can conclude that organisational structure and culture very much incorporates the possibility of collective moral responsibility.

Looking at the two factors of Larry May mentioned in this essay (page 8), the author would convey that groups/teams inside organisations are the most suitable types of collectives for applying this concept. The structure of an organisation provides the relationship between the employees and team workers in a specific way that they are actually related in their actions. This creates so called collective action. This relationship also creates intentions of not only individual type but a group type, where each of the members follows the same pattern of thinking. What is also crucial is that all of organizations have representative bodies, which also shows that according to the concept of Larry May, they can be held liable for their decisions. In this essay the author has listed the arguments 'for' and 'against' the concept of collective moral responsibility.

She has also touched a concept of corporate social responsibility (CSR), which in the case of organisations, implies the concept of collective moral responsibility. This concept is extremely important in today's business environment. It is used for various purposes and has proved its' existence. From the authors point of view, CSR is directly connected with collective responsibility, since organisations are collectives. CSR is one of the most important applications of collective moral responsibility in practice. By building a simple assumption 'if CSR then collective moral responsibility' and using a method of logical deduction, the proved existence of collective moral responsibility occurred.

To conclude, the author would like to assert that increasing value and concern towards Corporate Social Responsibility and its implications will have to lead to a creation of relevant, practical, logical, and ethical framework of identifying the notion of collective moral responsibility and giving it a measure, which has not existed before. 


\section{REFERENCES}

Aristotle, (1985) The Nicomachean Ethics. Translated by Terence Irwin. Indianapolis: Hackett Publishing Co.

Downie, R. S., (1969) ' Collective Responsibility', Philosophy 44: 66-69.

Eshleman, A. (2009), ' Moral Responsibility', The Stanford Encyclopedia of Philosophy (Winter 2009 Edition) (Available at: http://plato.stanford.edu/entries/moral-responsibility/) (Accessed on 16.04.12).

French, P. (1984) Collective and Corporate Responsibility. New York: Columbia University Press.

Friedman, M. and May, L. (1985) ' Harming Women as a Group, Social Theory and Practice', 11: 218-221.

Hobbes, T. (1651), ' Leviathan', New York: Penguin, 1968.

Journal of Law and Policy (2010), 'From Moral Agency to Collective Wrongs; Re-thinking Collective Moral Responsibility', Volume 19

Lewis, C.I. (1955) The Ground and the Nature of Right. New York: Columbia University Press.

Lewis, H.D. (1948) ' Collective Responsibility', Philosophy, 24: 3-18.

Louis, P. Pojman er James, Fisher. (2005) 'Ethics Discovering Right and Wrong", 6e.

May, L. and Hoffman, S. (eds.), (1991) Collective Responsibility: Five Decades of Debate in Theoretical and Applied Ethics, Savage, MD: Rowman and Littlefield.

May, L. (1992) Sharing Responsibility. Chicago: University of Chicago Press.

Plato (after 399 BC) Euthyphro, 5e-6a.

Weber, M. (1914) 'Economy and Society', Vol. 1, Berkeley: University of California Press, 1978. 